\title{
Ladakh Dental Clinic: The Local-Imported Modulars Negotiating Contradictory Material Practices in Remote Cities
}

\author{
SASA ZIVKOVIC \\ Cornell University
}

\author{
LESLIE LOK \\ Cornell University
}

\begin{abstract}
This paper outlines the design and construction of the Ladakh Dental Clinic project as a case study for hybrid localimported material building practices. Referencing local vernacular types as well as comparable rapid assembly systems deployed in India and beyond for other development projects, the paper discusses opportunities and shortcomings of such building strategies. In admirably positivistic modernist spirit, modular construction is often praised as the harbinger or exporter of progress and, at times, architectural advancement. Regularly choking on its own ambitions, successful modular construction largely remains an architectural fantasy as it often struggles to overcome its totalitarian spatial tendencies and inherent inflexibility. Compared to local techniques and perhaps contradictory to its intent, modular construction has a tendency to operate top-down instead of bottom-up. The Ladakh Dental Clinic project can be characterized as a result of its contradictory constraints and multi-client requirements. Necessitating both local construction and imported modular systems due to financial limitations, sponsorship opportunities, future expandability, and a tight schedule, the clinic emerges as a strange hybrid oscillating between local (de-facto imported) Indian cast-in-place concrete construction and (imported) German prefabrication.
\end{abstract}

REMOTE CONTEXT AND LOCAL VERNACULAR BUILDING Building in remote cities such as Leh in India comes with distinct difficulties as there are few local resources and nearly all construction materials have to be trucked over treacherous mountain paths. Ladakh translates to "the land of High Passes" and is located at the northernmost tip of India in the remote Himalayas region. The city of Leh is situated in the Indus Valley, has a population of approximately 30,000 people, and is an important regional economic center which heavily relies on tourism ${ }^{1}$. Ladakh's landscape is characterized by an oscillation between dry high plateau and lush green valleys, supporting a largely agricultural economy and being home to a large Tibetan exile community. The Dalai Lama has his summer residence in Ladakh and is also a patron of the dental clinic project. Poverty levels in Ladahk are high and large parts of the population have insufficient access to dental - or medical care in the region. The culturally rich and diverse geographic region of Ladakh is part of the state of Jammu and Kashmir which is situated in close proximity to Pakistan as well as
China. Geographically and culturally, Ladakh is perhaps more related to Tibet than to the Indian subcontinent ${ }^{2}$.

As such, the local architecture shares a similar and limited material palate with Tibetan architecture, which uses mostly locally available resources such as stone and wood. The use of wood is both ornamental and structural: architecturally, wood articulates openings, shades, balconies. In traditional construction, wood beams are used as structural elements to create ceilings for single or multi-story buildings. Openings are deliberately small as the region is known as cold desert with night temperatures dropping to 4 degrees Celsius in summer and negative 14 degrees Celsius in winter. Throughout Ladakh, traditional building techniques are being replaced by omnipresent concrete frame and brick infill construction. Following a common structural "template," these buildings follow the logic of conventional concrete construction protocols. However, despite the proliferation of modern techniques, buildings in Ladakh aim to retain some of their local character through the deliberate use of wood ornamentation.

\section{A CONCRETE VERNACULAR AND THE PROMISE OF MODULAR CONSTRUCTION}

Utilizing Ladakh's recent architecture as a case study, one can observe that the notion of "vernacular" has drastically shifted over the last decades. Concrete frame construction is a defacto vernacular technique in Ladakh: it is economical, readily available, and there are plenty of contractors who can build buildings using concrete frame structures. In India, architects such as Charles Correa have questioned predominant modernist strategies of mass-standardized construction: offering a new way to look at modern materials within a local context and enabling modular organizational strategies which adapt to local sites in scale, Correa defined what one could call a "vision for new global vernacular," using concrete frame construction with a brick infill ${ }^{3}$. His Tara Housing Complex in New Delhi is an excellent example for such a project: while the building adapts to local climatic conditions at the level of material and envelope, the building's typological organization enables high density without the spatial tensions normally associated with high unit quantities. Unfortunately, such projects remain a rare exception. Contrasting the romanticized "old" Ladakh "vernacular" known from postcards, the standard contemporary method of building in Ladakh and across 


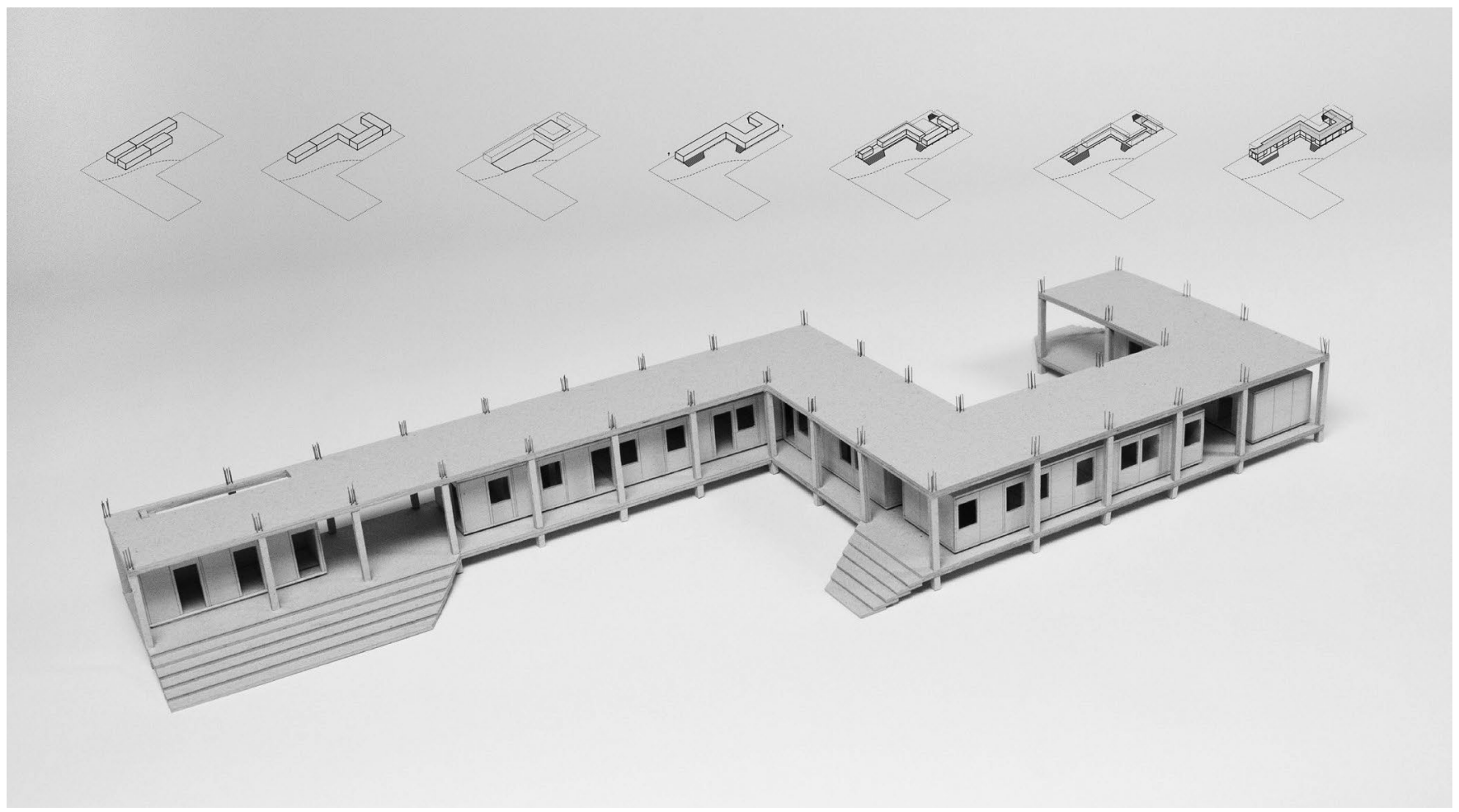

Figure 1: Hybrid local (concrete) and imported (wood) material systems inform the Ladakh Dental Clinic project.

the subcontinent relies on concrete frame construction. Such buildings are at times rough, industrial, and oftentimes fail to adapt to the local context.

Factory based precast construction in India - or modular construction in general - is often praised as the harbinger or exporter of progress and, at times, architectural advancement. Successful modular construction largely remains an architectural fantasy as it often struggles to overcome its totalitarian spatial tendencies and inherent inflexibility. Compared to local techniques (such as the vernacular concrete frame buildings) and perhaps contradictory to its intent, modular construction has a tendency to operate profoundly top-down instead of bottom-up. Therefore, within the context of Ladakh, modular precast construction is largely non-existent.

\section{PROJECT REQUIREMENTS}

In 2014, the Ladakh Dental Clinic project emerged as an alliance between a dentist, Dr. Roos, who started visiting Ladakh in the 90 's to treat patients pro bono in the summer, and Munitec $\mathrm{GmbH}$, a precast concrete connector company specializing in rapid assembly construction. Dr. Roos wanted to establish a permanent clinic in Ladakh, which would support his mission of providing free dental aid as well as operate as a regular dental clinic for a resident dentist. Munitec $\mathrm{GmbH}$ suggested to utilize its precast connector system (Reference) and develop a lightweight, shippable modular construction system for the clinic. Voehringer $\mathrm{GmbH}$, a company specializing in lightweight construction and coatings, generously agreed to sponsor the panels. As building materials and contractors are difficult to organize without establishing direct residence in Ladakh or speaking various local dialects, the initial project vision was to pre-fabricate the entire building in Germany, ship it to India, and assemble it during the short summer building season with a team of local and international volunteers. HANNAH (the co-authors of this essay) acted as an architectural consultant for the project. After reviewing project requirements and discussing options with all parties, it soon became clear that the initially proposed pre-fabricated building would not be able to provide the flexibility needed for later expansion. The lightweight system currently does not support multi-story building and is difficult to adapt locally. About one year into the project, it was decided to implement a concrete framework (or superstructure), constructed from locally available material and with a local contractor, so that the building could be expanded vertically later. The project can therefore be characterized as a result of its contradictory constraints and requirements: an unusual hybrid between local construction and German prefabrication (figure 1).

\section{DESIGN CONCEPT}

The clinic, about 200 square meters of enclosed space, is located on an L-shaped site south of the city of Leh, in a small village called Choglamsar. The property is directly adjacent to the Leh-Manali Highway, a two-lane road which serves as the main connection into the city and as a main thoroughfare across the mountains. Materially referencing regional vernacular construction types, the dental clinic consists of 

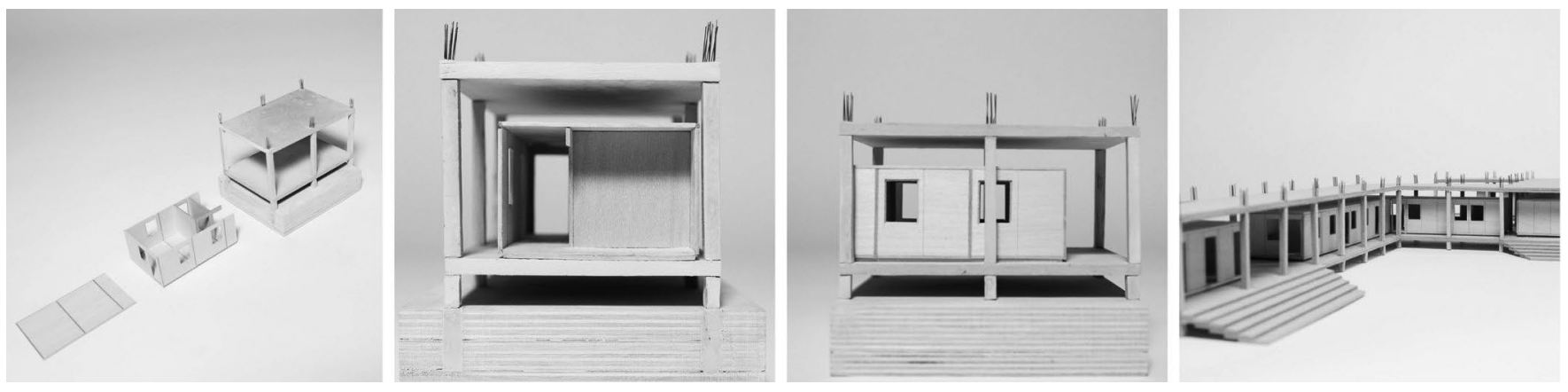

Figure 2: Two discrete architectural systems were deployed - prefabricated wooden SIP panels and cast-in-place concrete.

two discrete architectural systems, a cast-in-place concrete frame structure and wooden modular programmatic elements which provide the sanitary and climatic conditions necessary to house dental laboratory equipment (figure 2). Structural dimensions of the concrete superstructure are based on information from the local contractor. The building is raised three feet off the ground to protect against flooding. As is common in the region, all properties are surrounded by 6 foot walls. Arranged linearly, the building deforms to site conditions, meandering to create two distinct courtyards one private in the back for the resident dentist and one public in the front for the dental clinic. There are four major programmatic elements: the clinic, a storage unit, and two small apartments - one for a resident dentist, and one for visiting dentists. Breaking up programmatic elements into smaller volumes ensures sufficient privacy between the units. This design strategy creates an interplay of covered colonnade conditions, mixed with bigger places to rest, such as the stairs or the larger patio areas. In combination with the wooded elements, the concrete superstructure functions as a giant pergola, which encourages the use of outside spaces during the hot summer months and provides additional shelter from the cold during the harsh winter. The openness of the pergola creates a direct visual connection to the context: the river valley, the irrigation channel, and the mountains which surround the site.

\section{LOCAL CONCRETE CONSTRUCTION}

The concrete superstructure absorbs eventual snow loads for the prefabricated units (there is very little snow in Ladakh) and gives shelter from rain. Structural dimensions of the concrete superstructure are based on double-translated information through Skype conversation from the local contractor: 1 foot columns and a maximum clear span of 16 feet are the local building standard in Ladakh. Based on those dimensions, the design consultant team proposed a structural layout for the concrete building which alternates between 16 foot square bays at the ends and corners, and $12 \times 16$ foot regular bays in between. The proposed ceiling height was 11 feet, enabling easy access during construction and ensuring that the programmatic wooden boxes can be assembled properly. A drainage plan, including the location of two seepage pits, was provided to the contractor by the architectural consultant team. After receiving all relevant information and drawings, the contractor took over responsibility for the concrete structure and started construction in early spring 2016. Linear strip foundations were first constructed using local stone masonry techniques and locally available materials. All concrete work was executed predominantly by hand, utilizing buckets and small cement mixers. The bottom concrete frame was constructed over a period of multiple weeks using simple techniques and formwork. Following the construction of the columns, the beams and ceiling were constructed, supported by locally grown 2-inch diameter round wood scaffolding (figure 3). The concrete floor was poured last, supported on a gravel bed.

Considerable alterations occurred during the construction of the concrete superstructure, some improving the usability of the structure, others endangering the completion of the project: one of the structural bays at the end of the building was shortened by four feet, the stair to the second floor was relocated to the exterior of the structure, the location and shape of the exterior landscape stairs were altered, and a three-foot walkway cantilever was constructed running along the entire south-east side of the building. Most importantly, the height of the concrete structure was lowered to approximately 9 feet and 6 inches between beams and slab, posing a considerable problem for the wooden programmatic volumes. The lowered height of the concrete structure required adjustments to the wood foundations of the programmatic volumes and made it considerably more difficult to install roof panels and the roofing system. In the end, despite nonexistent communication between the design consultant team and the contractor, the concrete structure proved sufficient for the installation of the prefabricated elements.

\section{IMPORTED PREFABRICATED CONSTRUCTION SYSTEM}

Utilizing Munitec GmbH connector technology, the team developed a lightweight prefabricated construction system from scratch. All modules are connected with plug-and-play connectors adapted from concrete precast construction, allowing for the rapid assembly of a building in remote locations without tools or heavy machinery. The custom designed 

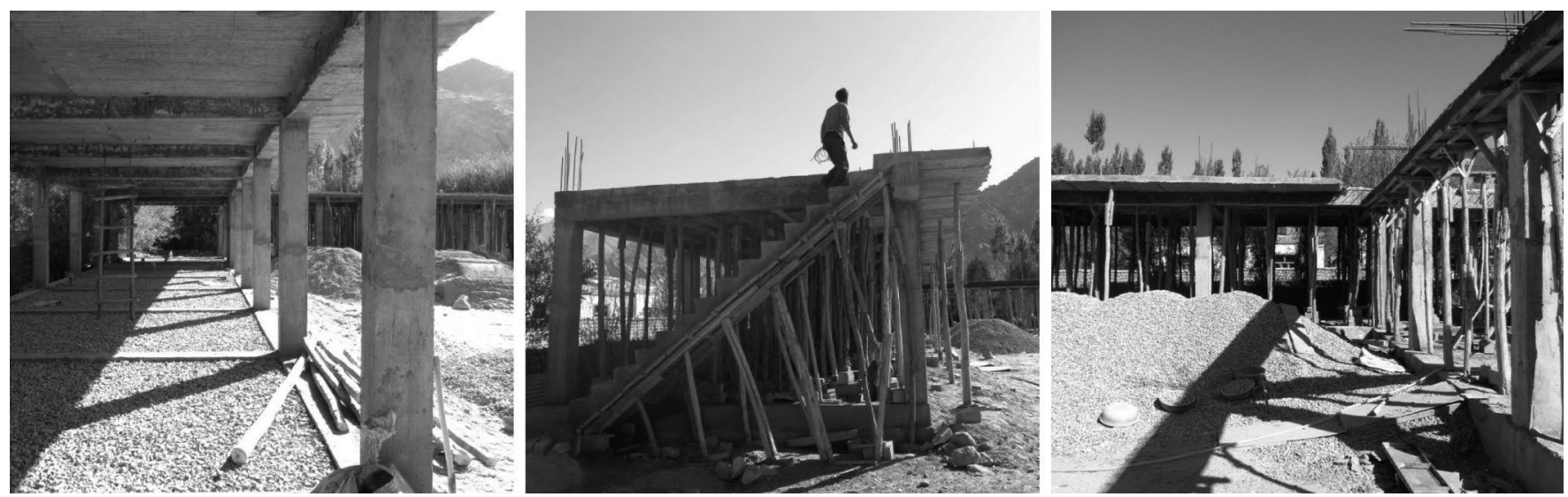

Figure 3: (above) Structural dimensions of the concrete superstructure are based on information from the local contractor: 1 foot columns and a maximum clear span of 16 feet are the local building standard in Ladakh.
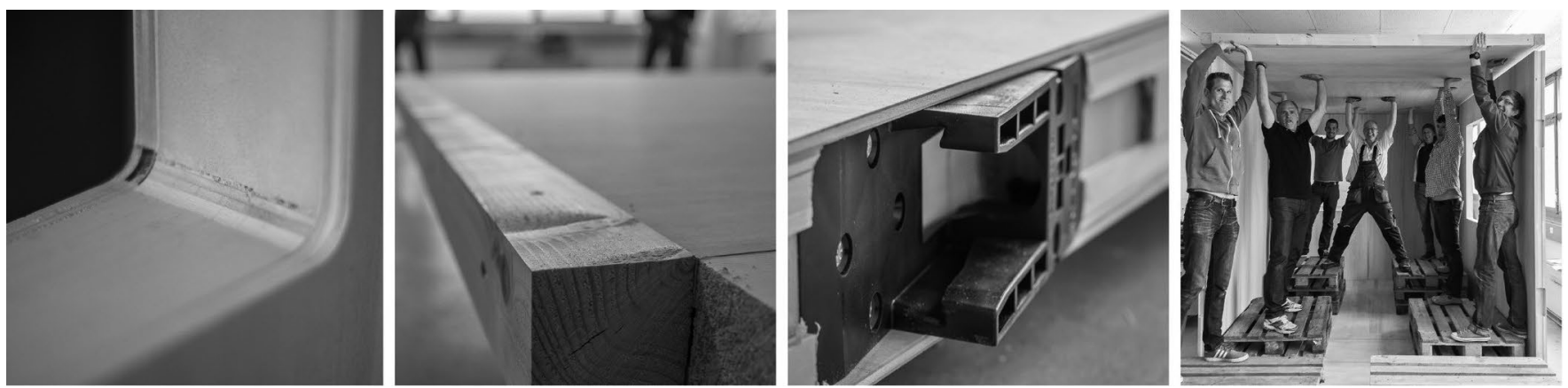

Figure 4: A mock-up sample room was constructed in Germany to test the feasibility of the prefabrication system.

Structural Insulated Panels (SIP) weigh under $30 \mathrm{~kg}$, measure 1.2 by 2.4 meters, and are complimented by a modular wooden frame system offsetting the material thickness of the panels. In order to construct a building, three types of panels were developed: (1) the wall, ceiling, and floor panels have no opening and can be used to construct any vertical or horizontal surfaces, (2) the window panels have a $0.9 \times 1.2$ meter opening in which standard windows can be installed, (3) the door panels have a $0.9 \times 2.1$ meter opening to accommodate a standard door frame.

The SIP panels are $9 \mathrm{~cm}$ thick and consist of three layers of material: a $1 \mathrm{~cm}$ plywood sheet, $7 \mathrm{~cm}$ of insulation, and an additional $1 \mathrm{~cm}$ plywood sheet. To reinforce the structural properties of the panels, a $7 \mathrm{~cm}$ square wooden frame runs along the edge of the panels and is glued flush into the assembly. Large-scale CNC machines at Voehringer $\mathrm{GmbH}$ cut window and door openings into the surfaces. Each panel has six possible points of connection along the edges, which are also CNC milled to precisely fit the connectors. BASECON, a male-female fiberglass load connector that is suitable for transmitting loads and accommodating media connectors, is used to attach panels to each other. The modular wooden frame is connected to the panels using large wood screws and lag bolts. A mock-up sample room was constructed in
Germany to test the feasibility of the system (figure 4). The direction of panel installation has to be taken into account during planning and assembly, which increases the complexity of construction. On the exterior, the wood is treated using standard wood coatings to resist excessive weathering. The light roof cover consists of a custom-made truck tarp that gets attached to the upper portion of the side walls. Leftover pallets from the transport are mounted on the concrete and act as foundations for the prefabricated wooden structure. In addition to its determined use as a dental clinic, the lightweight structure is designed to perform as a flat-pack prototype for disaster relief shelters that require fast construction and minimum planning.

\section{LOCAL-IMPORTED BUILDING ASSEMBLY}

After the ultra-lightweight wooden SIP panel modules were prefabricated in Germany, they were shipped to Mumbai via Rotterdam in two overseas fright containers. However, due to difficult transportation logistics and customs import procedures, the prefabricated building components arrived one year behind schedule. Upon arrival at the port of Mumbai in 2017, the boxes embarked on a 900-mile journey to Leh in a fleet of small trucks, traveling on one of the most difficult and dangerous roads in the world. Once in Ladakh, the clinic was assembled by a large group of volunteers: the wooden panels, 

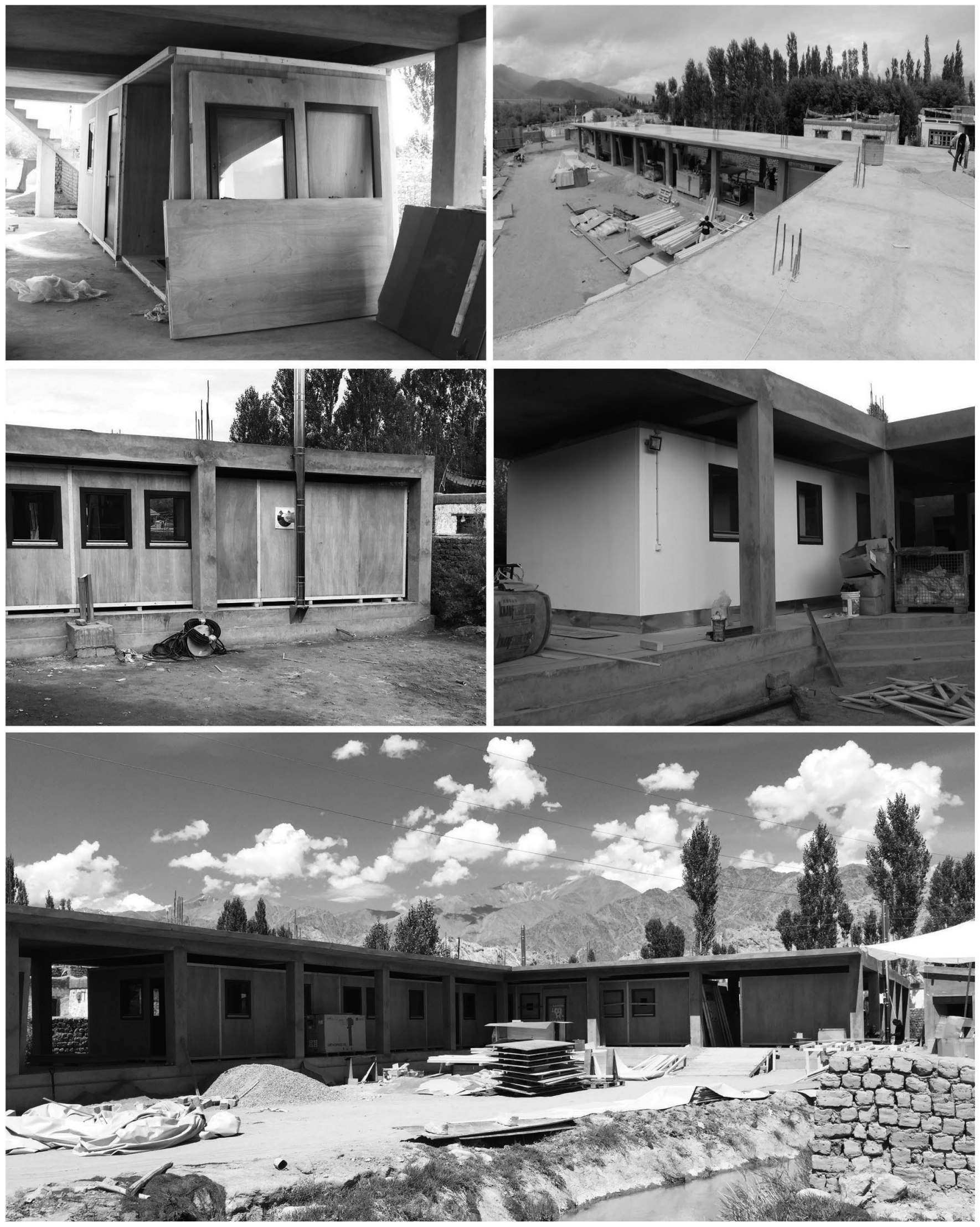

Figure 5: Ladakh Dental Clinic under construction in summer 2017. 
loaded and packed according to their use in the structure, were erected first. Fortuitously, even though the height of the concrete structure was changed, it was built just barely tall enough to fit the wooden boxes. Once the prefabricated structure was completed, the team installed electrical wiring utilizing a German surface mounted conduit system. Each of the programmatic elements is heated by a coal burning oven and boiler system, connected by surface-mounted pipes to a series of radiators located in critical locations. Laminate flooring was brought from Germany and installed on site. All interior walls and ceilings were painted white before the clinic equipment, sanitary systems, and built-in furniture were installed. On the exterior, the truck tarp roof system was installed along with metal flashing baseboards to protect and to enclose the wood pallet foundations.

Unfortunately, in an effort to make the building appear more "local" and to eradicate its prefabricated roots, it was decided to paint the exterior white (like the local stone architecture). The contradictory nature of the project, its struggle with being both local and imported, is clearly emphasized by such conceptual clashes. Occurring throughout the structure, these tensions render the building unique and compelling nevertheless. It is a work of multiple entities, designers, cultures, and authors. The conflicting agendas are clearly legible and evident in the resulting end product, a truly multi-hybrid material construction system (figure 5).

\section{MODULAR CONSTRUCTION HYBRIDS - A SOLUTION FOR REMOTE REGIONS?}

Comparing the Ladakh Dental Clinic with other development projects, it has to be acknowledged that comprehensive development aid beyond the construction of a clinic was never the focus of this undertaking. However, "lo-fab" projects such as the Ilima Primary School ${ }^{5}$ and Gheskio Cholera Treatment Center ${ }^{6}$ by MASS Design Group show that there is an opportunity - for design and for the community - when architecture engages a local context more actively. As mentioned earlier, the Ladakh Dental Clinic project is a result of its contradictory constraints and multi-client requirements. While prefabrication presents certain opportunities, it also limits architectural possibilities within a remote context such as Ladakh. The non-modifiable IKEA emergency shelter ${ }^{7}$ provides a good example for the limits and opportunities of modular prefabrication. In the end, critically questioning the work, the promise of effortless and quick construction was not fulfilled: due to delays in shipment and an increase in planning efforts, the project finished one year behind schedule. While there is no comprehensive cost estimate available to the authors, it is our impression that local construction could have saved overall building costs.

Despite all difficulties, the architectural consultants conclude that the project as a whole is a success. It provides much needed facilities for dental care in the Ladakh region and demonstrates the relative feasibility of collaborating and successfully executing a building project across three continents. Raising critical questions about the use of prefabrication in remote areas, the Ladakh Dental Clinic serves as a case study for a collaborative architectural project that aims to merge different construction methods and ways of thinking. Within a broader disciplinary context, the project is simultaneously simple and highly complex when considering the entire architectural process. It is both local and foreign. It is anachronistic and forward looking. For better or worse, it merges "high-tech" and "low-tech" material economies. With humble means, the pro-bono project aims to innovate and to advance disciplinary knowledge and material practices for development projects in remote cities and regions: through the design and implementation of a lightweight panel construction system, through integration of local construction techniques, through new modes of international volunteer collaboration, and through alternate models of architectural practice.

\section{ACKNOWLEDGEMENTS}

This pro-bono project is the result of a large volunteer effort: Architectural consulting: HANNAH Design Office in collaboration with Architect Dr. Frank Prochiner, principals in charge: Sasa Zivkovic, Alexander Chmarin, Leslie Lok, Alexander Graf / Project Management and Construction Planning in Germany: Joachim Wiegmann GmbH, Joachim Wiegmann / Project Development: Ladakh Medical Aid gGmbH, Dr. Rainer Roos, Ulrike Roos / Carpenter Works: Joachim Wiegmann, Felix Wiegmann, Simon Maier / Plumbing and Heating: ALSanitär, Andreas Lutz, Syvia Lutz, Thomas Höhn / Electrical Engineering: Natalino Meixner-Malandrino, Hochschule Trier; Stefan Ameling, Simon Lemling, Tobias Schmalen, Rene Thull, Johannes Weber, Markus Neukirch, Maximilian Schmalen, Chistian Schäfer / Panel Fabrication: Voehringer $\mathrm{GmbH}$, Walter Tacke / Connector System: Munitec GmbH, Dr. Ing. Frank Prochiner / Dental Clinic Consultant: Henry Schein Dental GmbH, Thomas Hertweck / Construction Management in Ladakh: Dr. Kunsang Dechen / Dental Consulting: Hans Kopecek/Travel: Roland Tröndle, Jürgen Reinbold

\section{ENDNOTES}

1. Michaud, Jean. "A Historical Account of Modern Social Change in Ladakh (Indian Kashmir) with Special Attention Paid to Tourism 1." International Journal of Comparative Sociology 37, no. 3 (1996): 286-300.

2. Rizvi, Janet. "Ladakh: crossroads of high Asia." OUP Catalogue (1999).

3. Correa, Charles. Housing \& urbanisation. Urban Design Research Institute, 1999. pp 20-23

4. Prochiner, Frank. "Munitec fast connectors - key technology for prefab houses." In Advances in Building Technology, pp. 367-371. Elsevier, 2002.

5. John Cary, "In Haiti, a Building Fights Cholera" The New York Times, published on Jan. 1, 2017, accessed on July 22, 2018 https://www.nytimes. com/2017/09/12/opinion/fighting-cholera-haiti.html

6. Laura Raskin, "Ilima Primary School," Architectural Record, published on Sept. 12, 2017, accessed on July 24, 2018 https://www.architecturalrecord.com/ articles/11397-ilima-primary-schoo

7. Oliver Wainwright, "Why lkea's flatpack refugee shelter won design of the year," The Guardian, published on Jan. 27, 2017, accessed on July why-ikea-flatpack-refugee-shelter-won-design-of-the-year8 